\title{
Intrauterine fetal death associated socio-demographic factors and obstetric causes: a retrospective study
}

\author{
Asma Hassan Mufti*, Samiya Mufti, Nasir Jeelani Wani
}

Department Obstetrics and Gynaecology, Government Medical College Srinagar, Jammu and Kashmir, India

Received: 29 June 2020

Accepted: 20 August 2020

\section{*Correspondence:}

Dr. Asma Hassan Mufti,

E-mail: asma.h.mufti14@gmail.com

Copyright: (C) the author(s), publisher and licensee Medip Academy. This is an open-access article distributed under the terms of the Creative Commons Attribution Non-Commercial License, which permits unrestricted non-commercial use, distribution, and reproduction in any medium, provided the original work is properly cited.

\section{ABSTRACT}

Background: The death of a fetus is emotionally traumatic for the parents. It is also distressing for the treating obstetrician. Besides being emotionally challenging, fetal demise raises a lot of questions and increases an obstetrician's medicolegal risk. The aim of this study was to identify various maternal conditions and socio-demographic factors associated with fetal death and to find the preventable causes of fetal death.

Methods: A retrospective observational study was undertaken at Lalla Ded Hospital, Srinagar, Kashmir - a tertiary care centre. The cases of singleton intrauterine fetal deaths (IUFD) with either ultrasound reports proving IUFD or diagnosed on clinical examination by absence of fetal heart sound with gestational age $>28$ weeks were included. Exclusion criteria includes molar pregnancy and multiple pregnancy.

Results: Still birth rate in our study was 19.6 per 1000. Most of the patients with stillbirth belonged to age group of 2130 years accounting for $67.1 \%$ of all cases. Unbooked cases comprised of 58.9\%. Most of the study patients i.e. $74.7 \%$ belonged to lower middle class. In our study $39 \%$ of stillbirth cases were in the range of 28-32 gestational weeks followed by $33.6 \%$ cases in 33-37 gestational weeks. Maternal hypertensive disorders had a strong association with IUFD 33.6\% (pre-eclampsia 27.4\%, eclampsia 6.2\%). This was followed by placental abruption comprising $11.7 \%$. Gestational diabetes and severe anaemia accounted for $6.2 \%$ and $3.4 \%$ respectively. Gross congenital anomalies and fetal infections contributed $2.7 \%$ and $2 \%$ respectively.

Conclusions: Routine antenatal checkups with identification of high risk pregnancies, better access to emergency obstetric care especially during labor, emphasis on institutional deliveries community birth attendant training should help in reducing stillbirth rates in developing countries. Optimal evaluation for future pregnancy is necessary. Counseling and support group should be involved.

Keywords: IUFD, Stillbirth, Incidence

\section{INTRODUCTION}

Every woman wants conception to culminate in motherhood. The death of a fetus is emotionally traumatic for the parents. It is also distressing for the treating obstetrician. Besides being emotionally challenging, fetal demise raises a lot of questions and increases an obstetrician's medicolegal risk.

Fetal demise is defined differently around the world, based on gestational age and weight of fetus. According to World
Health Organization (WHO), intra uterine fetal death (IUFD) is defined as death prior to complete expulsion or extraction from mother of products of conception after the age of viability (28 weeks according to Indian references and according to American College of Obstetricians and Gynaecologists, ACOG 20 weeks). ${ }^{1,2}$ The National Centre for Health Statistics, USA divides fetal death into two categories: Early (20-27weeks) and Late (>28 weeks). ${ }^{3}$ Prevalence of IUFD and stillbirth is expressed as number of fetal deaths per 1000 live births. Range of incidence varies in different countries, ranging from five in 1000 
births in high income countries and 36 in 1000 births in developing countries. ${ }^{4,5}$

Prevalence of perinatal deaths in a society is the direct indicator of the quality of antenatal care in the country. ${ }^{6}$ IUFD reflects maternal as well as perinatal health of a given population. One of the methods of reducing fetal death is recognizing its causative factors and improving them. In most cases, deaths with known causes are preventable. The problem is more difficult in death with unknown causes. In the developing countries, the bulk of intrauterine fetal deaths are intrapartum and are attributed commonly to the avoidable factors. In contrast, stillbirth in developed countries is largely ante-partum with no apparent cause. ${ }^{7}$

Maternal hypertension, diabetes mellitus, renal disease and autoimmune disorders, as well as placentation abnormalities and fetal congenital anomalies, are examples of conditions that can place the pregnancy at high risk of fetal compromise. Commonly associated antepartum conditions include congenital malformation, congenital fetal infection, antepartum haemorrhage, preeclampsia and maternal disease such as diabetes mellitus. The common causes of intrapartum death include placental abruption, maternal and fetal infection,cord prolapse, idiopathic hypoxia-acidosis and uterine rupture. ${ }^{8,9}$ Factors like illiteracy, poor socioeconomic condition and misbelieves that prevent women going to hospital for regular antenatal checkups contribute to increasing fetal mortality rates.

Stillbirth is an event which has always challenged the obstetricians. The mode of antepartum and intrapartum surveillance for fetal well-being has advanced in last few decade but the stillbirth rate has remained generally constant. In developed countries, it has been speculated that rising obesity rates and average maternal age might be behind the lack of improvement. ${ }^{9}$ In addition to any physical effects, stillbirth often has profound emotional, psychiatric and social effects on parents. By proper antenatal check-ups, the high-risk cases associated with poor outcomes can be identified.

The aim of this study was to identify various maternal conditions and socio-demographic factors associated with fetal death and to find the preventable causes of fetal death.

\section{METHODS}

Cases of intra-uterine fetal deaths at Lalla Ded Hospital, Srinagar - a tertiary care centre from November 2018 to November 2019 were included in the study. Number of cases studied were 146 .

A retrospective observational study was undertaken. The cases of intra-uterine fetal deaths with either ultrasound reports proving IUFD or diagnosed on clinical examination by absence of fetal heart sound were included.

\section{Inclusion criteria}

All cases of singleton IUFD > 28 weeks of gestation.

\section{Exclusion criteria}

Patients with molar pregnancy and multiple pregnancy were excluded from this study.

Detailed obstetric history, details about present complaints and duration of pregnancy, past obstetric performances and outcomes (including previous abortions, previous IUFD and associated toxemias) were studied. Various socio-demographic factors including age, parity and socioeconomic status were noted.

Those patients who had attended antenatal clinic at least thrice before delivery were considered booked cases. Fetal outcomes recorded included sex of the baby or any gross congenital malformations. The details of the mode of delivery included vaginal delivery, lower segment cesarian section (LSCS) and laparotomy.

Recorded data was analyzed to identify probable cause of IUFD. Results were obtained using the percentage method.

\section{RESULTS}

During the study period number of deliveries were 7465 out of which 146 were IUFDs. So, the still birth rate in our study was 19.6 per 1000 (Table 1).

Table 1: Number of IUFDs during study period.

\begin{tabular}{|lll|}
\hline Total deliveries & IUFDs & Still birth rate \\
\hline $\mathbf{7 4 6 5}$ & 146 & 19.6 \\
\hline
\end{tabular}

Table 2 describes demographic details. Out of 146 women where IUFD happened, $10.3 \%$ were $<20$ years, $67.1 \%$ were 20 -30 years, $21.9 \%$ were $31-40$ years and $0.7 \%$ were $>40$ years of age. $57 \%$ women were multigravida and $43 \%$ were primigravida.

Majority of the patients were unbooked (57.5\%) and presented through obstetric casualty. About $26 \%$ of cases belonged to upper middle socioeconomic status and $74 \%$ belonged to lower middle socioeconomic study group (Table 2).

Details of IUFD were also noted (Table 3). 55.5\% of IUFDs were male fetus. Majority of cases had happened in $28-32$ week period (39\%), followed by $33.6 \%$ cases in $33-$ 37 week period.

Most of deliveries were preterm normal vaginal deliveries (71.9\%). 19.2\% cases had full term normal vaginal delivery. LSCS was done in $8.2 \%$ of cases. There was one case of rupture uterus for which laparotomy was done. 
Table 2: Demographic details.

\begin{tabular}{|lll|}
\hline Age (in years) & No. of patients & Percentage \\
\hline$<20$ & 15 & 10.3 \\
\hline $21-30$ & 98 & 67.1 \\
\hline $31-40$ & 32 & 21.9 \\
\hline$>40$ & 1 & 0.7 \\
\hline Parity & & \\
\hline Primigravidae & 62 & 42.5 \\
\hline Multigravida & 84 & 57.5 \\
\hline Registration & & \\
\hline Booked & 60 & 41.1 \\
\hline Unbooked & 86 & 58.9 \\
\hline Socioeconomic status & \\
\hline Upper middle & 37 & 25.3 \\
\hline Lower middle & 109 & 74.7 \\
\hline
\end{tabular}

Table 3: Details of IUFDs.

\begin{tabular}{|lll|}
\hline Gender of babies & $\begin{array}{l}\text { No. of } \\
\text { patients }\end{array}$ & Percentage \\
\hline Male & & \\
\hline Female & 81 & 55.5 \\
\hline Gestational age (in weeks) & 65 & 44.5 \\
\hline $28-32$ & 57 & 39 \\
\hline $33-37$ & 49 & 33.6 \\
\hline $38-40$ & 34 & 23.3 \\
\hline$>40$ & 6 & 4.1 \\
\hline Mode of delivery & & \\
\hline Preterm vaginal delivery & 105 & 71.9 \\
\hline Full term vaginal delivery & 28 & 19.2 \\
\hline LSCS & 12 & 8.2 \\
\hline Laprotomy & 1 & 0.7 \\
\hline
\end{tabular}

Table 4 enlists causes and risk factors of IUFD and their incidences.

In our study, most common identifiable cause of IUFD was pre-eclampsia and was seen in $27.4 \%$ cases. It was followed by Abruption $11.7 \%$, eclampsia $6.2 \%$ and pregnancy complicated by diabetes mellitus $6.2 \%$.

Cause of IUFD was unidentifiable in $13.8 \%$ of cases.

Table 4: Causes and risk factors of IUFD.

\begin{tabular}{|lll|}
\hline Causes & No. of cases & Percentage \\
\hline Pre-eclampsia & 40 & 27.4 \\
\hline Eclampsia & 9 & 6.2 \\
\hline Abruption & 17 & 11.7 \\
\hline Placenta previa & 4 & 2.7 \\
\hline Polyhydramnios & 1 & 0.7 \\
\hline Oligohydramnios & 2 & 1.4 \\
\hline Severe anemia & 5 & 3.4 \\
\hline Diabetes mellitus & 9 & 6.2 \\
\hline
\end{tabular}

\begin{tabular}{|lll|}
\hline Causes & No. of cases & Percentage \\
\hline $\begin{array}{l}\text { Maternal medical } \\
\text { diseases }\end{array}$ & 5 & 3.4 \\
\hline Rh-incompatibility & 2 & 1.4 \\
\hline $\begin{array}{l}\text { Cholestasis of } \\
\text { pregnancy }\end{array}$ & 5 & 3.4 \\
\hline $\begin{array}{l}\text { Gross congenital } \\
\text { anomalies }\end{array}$ & 4 & 2.7 \\
\hline TORCH infections & 3 & 2 \\
\hline Severe IUGR & 5 & 3.4 \\
\hline $\begin{array}{l}\text { Meconium aspiration } \\
\text { syndrome }\end{array}$ & 3 & 2 \\
\hline PROM >48 hours & 3 & 2 \\
\hline Post maturity & 1 & 0.7 \\
\hline Cord accidents & 2 & 1.4 \\
\hline Hand prolapse & 1 & 0.7 \\
\hline Obstructed labour & 4 & 2.7 \\
\hline Rupture uterus & 1 & 0.7 \\
\hline Unexplained & 20 & 13.8 \\
\hline
\end{tabular}

\section{DISCUSSION}

Stillbirth rate in our study was $19.6 / 1000$ births, with total of 146 IUFDs out of 7465 births. While many developed countries have stillbirth rates as low as 3-5/thousand births, most developing countries have rates that are tenfold higher. ${ }^{10}$ The incidence rate reported from various centers in India is 24.4-41.9\%. ${ }^{11-16}$ One reason of high stillbirth at our hospital could be due to it being a tertiary care referral center where all major obstetric complications identified in the peripheral centers are referred to. The other reason could be due to less number of institutional deliveries due to various reasons like low socioeconomic status, illiteracy and the deficiency of monitoring facilities in rural areas.

In our study, most of the patients with stillbirth belonged to age group of 21-30 years accounting for $67.1 \%$ of all cases. This is in accordance with the study conducted by Nayak et al. ${ }^{17}$ Similar results were obtained by Kumari et al and Vaishali et al. ${ }^{18,19}$ The reason for this is due to early marriages in our setup and most of the referrals are from rural areas where early marriages are a norm. The relation between parity and stillbirth revealed a high incidence among multiparous women which accounted for $57.5 \%$ of all IUFDs. The reason for this may be advanced age and associated medical conditions. This is in accordance with study by Bhatia et al but contradicts results of Nayak et al where incidence is high among primiparas. ${ }^{20}$

According to WHO minimum number of antenatal visits should be four with Indian guidelines reducing that to three, for optimal care during pregnancy. Most of the IUFDs in our study were unbooked cases comprising of $58.9 \%$. Poor socioeconomic condition, illiteracy and false traditional beliefs were the contributory factors. Most of the study patients i.e. $74.7 \%$ belonged to lower middle class. Similar results were found by Bhatia et al and Kumari et al. ${ }^{18,20}$ 
In our study $39 \%$ of stillbirth cases were in the range of 28-32 gestational weeks followed by $33.6 \%$ cases in $33-37$ gestational weeks. Most of cases were associated with hypertensive disorders of pregnancy. As far as gender is concerned most of the IUFDs were male comprising $55.5 \%$.

Maximum number of patients were delivered vaginally in our study accounting for $91.1 \%$ cases. The modes of delivery and the percentage of LSCS (8.2\%) were similar as compared to study by Bhatia et al, Kumari et al whereas it is higher in study by Vaishali et al. ${ }^{18-20}$ Laprotomy was done in a case of uterine rupture. Vaginal delivery was main mode of delivery, unless there were specific indications for LSCS. Oxytocin and prostaglandins were used for induction and augmentation wherever needed. The most common indications for LSCS were placenta previa, previous caesarean section (two or more) and transverse lie.

In our study, maternal hypertensive disorders had a strong association with IUFD $33.6 \%$ (pre-eclampsia $27.4 \%$, eclampsia $6.2 \%$ ). This is similar to the study done by Kumari et al (30\%) and Lucy et al (32.8\%). Placental insufficiency is often implicated in still birth particularly in the setting of pre-eclampsia. ${ }^{18,21}$

Second most common cause of IUFD in our study was placental abruption comprising $11.7 \%$. Gestational diabetes and severe anaemia accounted for $6.2 \%$ and $3.4 \%$ respectively. Gross congenital anomalies and fetal infections contributed $2.7 \%$ and $2 \%$ respectively.

Other causes of stillbirth in our study were cholestasis of pregnancy (3.4\%) and Rh incompatibility (1.4\%).

Obstructed labour accounted for $2.7 \%$ cases reflecting poor obstetric care and paucity of referral resources in peripheral areas. Cord accidents were seen in $1.4 \%$ cases.

Sudden unexplained cause of IUFD still remains a major problem among the obstetricians and hence more studies need to be carried out in this area. In our study, unexplained IUFD was seen in $13.8 \%$ of cases.

\section{CONCLUSION}

Stillbirth remains one of the most common adverse outcomes of pregnancy, yet is among the least studied. Evaluation of the causes of stillbirths are important initial steps in reducing its incidence.

Routine antenatal checkups with identification of high risk pregnancies, better access to emergency obstetric care especially during labor, emphasis on institutional deliveries community birth attendant training should help in reducing stillbirth rates in developing countries. Optimal evaluation for future pregnancy is necessary. Counselling and support group should be involved.
Funding: No funding sources

Conflict of interest: None declared

Ethical approval: The study was approved by the Institutional Ethics Committee

\section{REFERENCES}

1. Donald I. Prolonged pregnancy and IUFD in practical obstetric problems, Wolter Kluwer, 2014;7th edition: 435 .

2. Kochenour N. Management of foetal demise. Clin Obstet and Gynaecol. 1987;30(2):322-30.

3. MacDorman MF, Kirmeyer SE, Wilson EC. Fetal and perinatal mortality, United States 2006. National vital statistics reports. Hyattsville, MD:National Centre for Health Statistics. 2012;60(8).

4. Ruth C. Frets, etiology and prevention of still birth, Am J Obstetr Gynecol. 2005;193:1923-35.

5. Cousens S, Blencowe H, Stanton C, Chou D, Ahmed S, Steinhardt L, et al. National, regional, and worldwide estimates of stillbirth rates in 2009 with trends since 1995: a systematic analysis. Lancet. 2011;377:1319-30.

6. Richardus JH, Graafmans WC, Verloove-Vanorick S, Mackenbach JP. The perinatal mortality rate as an indicator of quality of care in international comparisons. Med Care. 1998;36(1):54-66.

7. Archibong EI, Sobande AA, Asindi AA. Antenatal intrauterine foetal death; a prospective study in a tertiary hospital in western South Arabia. J Obstet Gynaecol. 2003;23(2):170-3.

8. Confidential Enquiry into Maternal and Child Health (CEMACH). Perinatal Mortality 2007: United Kingdom. CEMACH: London, 2009.

9. Confidential Enquiry into Maternal and Child Health (CEMACH). Perinatal Mortality 2006: England, Wales and Northern Ireland. CEMACH: London, 2008.

10. McClure EM, Phiri M, Goldenberg RL. Stillbirth in developing countries; a review of literature. Int J Gynaecol Obstet. 2006;94(2):82-90.

11. Misra PK, Thakur S, Kumar A, Tandon S. Perinatal mortality in rural India with special reference to high risk pregnancies. J Trop Pediatr. 1993;39:41 4.

12. Dasgupta S, Saha I, Mandal AK. A study on profile of stillbirths. J Indian Med Assoc. 1997;95:175-8.

13. Kumari R, Mengi V, Kumar D. Maternal risk factors and pregnancy wastage in a rural population of Jammu District. JK Sci. 2013;15:82 5.

14. Shah U, Pratinidhi AK, Bhatlawande PV. Perinatal mortality in rural India: A strategy for reduction through primary care. I Stillbirths. J Epidemiol Community Health. 1984;38:134 7.

15. Jadhav MA, Christopher LG. Perinatal mortality in Vellore. Part I: A study of 21,585 infants. Indian J Pediatr. 1986;53:347 52.

16. Bai NS, Mathews E, Nair PM, Sabarinathan K, Harikumar C. Perinatal mortality rate in a south Indian population. J Indian Med Assoc. 1991;89:97 8. 
17. Nayak K, Vaishali N, Pradeep GR. Causes of stillbirth. J Obstet Gynaecol India. 2008;58(4):314-8.

18. Kumari C, Kadam NN, Kshirsagar A, Shinde A. Intrauterine fetal death: A prospective study. J Obstet Gynecol India. 2001;51(5):94-7.

19. Vaishali N, Korde N, Gaikwad PR. Causes of stillbirth. J Obstet Gynaecol India. 2008;58(4):314-8.

20. Bhatia T, Narshetty JG, Bagade P, Kulkarni A, Rai M. Clinical study of cases of intrauterine foetal death in a tertiary centre. Int J Res Med Sci. 2016;4:800-5.
21. Lucy D, Satapathy Umakant, Panda Niharika. Perinatal mortality in a referral hospital of Orissa-10 year review. J Obstet Gynaaecol India. 2005;55(6):517-20.

Cite this article as: Mufti AH, Mufti S, Wani NJ. Intrauterine fetal death associated socio-demographic factors and obstetric causes: a retrospective study. Int J Reprod Contracept Obstet Gynecol 2020;9:402731. 